\title{
Efficacy and Safety of the Chinese Patent Medicine Yuquan Pill on Type 2 Diabetes Mellitus Patients: A Systematic Review and Meta-Analysis
}

\author{
Sihan Peng $\mathbb{D}^{1,2}$ Ziyan Xie, ${ }^{1,2}$ Xiyu Zhang, ${ }^{1,2}$ Chunguang Xie, ${ }^{1}$ Jian Kang, ${ }^{1}$ Haipo Yuan, \\ Gang $\mathrm{Xu},{ }^{1,2}$ Xiangeng Zhang, ${ }^{3}$ and Ya Liu $\mathbb{1}^{1}$ \\ ${ }^{1}$ Hospital of Chengdu University of Traditional Chinese Medicine, Chengdu, Sichuan, China \\ ${ }^{2}$ Chengdu University of Traditional Chinese Medicine, Chengdu, Sichuan, China \\ ${ }^{3}$ Sichuan Nursing Vocational College, Chengdu, Sichuan, China \\ Correspondence should be addressed to Ya Liu; liuyaya918@163.com
}

Received 7 October 2021; Revised 6 November 2021; Accepted 8 November 2021; Published 2 December 2021

Academic Editor: Youhua Wang

Copyright (C) 2021 Sihan Peng et al. This is an open access article distributed under the Creative Commons Attribution License, which permits unrestricted use, distribution, and reproduction in any medium, provided the original work is properly cited.

Background. Yuquan Pill (YQP), a Chinese patent medicine for the treatment of diabetes, is widely used in the treatment of diabetes and its complications in China. However, the efficacy of YQP on type 2 diabetes mellitus (T2DM) has not been completely assessed. The aim of this study is to evaluate the efficacy and safety of YQP in the treatment of T2DM. Materials and Methods. We systematically searched 9 databases for specific keywords from inception to Oct 2021. We included randomized controlled trials (RCTs) involving YQP in the treatment of T2DM without language limitation. The study conformed to the Cochrane Handbook and Review Manager software was used for data analysis. The weighted mean differences (WMDs) and 95\% confidence intervals (CIs) were used to measure treatment effects. Results. The final analysis included 10 publications. Analysis showed that the combination of YQP and conventional treatment was more effective than conventional treatment alone with regard to the levels of fasting blood glucose $(\mathrm{WMD}=-0.83 ; 95 \% \mathrm{CI}[-1.01,-0.66] ; p<0.00001)$, two-hour postprandial glucose $(\mathrm{WMD}=-1.40 ; 95 \% \mathrm{CI}$ $[-1.49,-1.31] ; p<0.00001)$, glycosylated hemoglobin (WMD $=-0.87 ; 95 \%$ CI $[-1.26,-0.49] ; p<0.00001)$, total cholesterol $(\mathrm{WMD}=-0.50 ; 95 \% \mathrm{CI}[-0.61,-0.39] ; p<0.00001)$, c-reactive protein $(\mathrm{WMD}=-0.58 ; 95 \% \mathrm{CI}[-0.88,-0.28] ; p=0.0002)$, and overall effective rate $(\mathrm{RR}=1.21 ; 95 \% \mathrm{CI}[1.12,1.31] ; p<0.00001)$. Conclusion. Evidence suggested that YQP might improve glucose and lipid metabolism and inflammation in patients with T2DM. Serious adverse events were not reported. The quality of the evidence analyzed was low and therefore our results should be interpreted with caution. More high-quality RCTs are now needed to verify these findings.

\section{Introduction}

Type 2 diabetes mellitus (T2DM) is a chronic metabolic disease that is characterized by elevated levels of blood glucose. The pathophysiology of T2DM is characterized by insulin resistance accompanied by reduced insulin secretion due to the dysfunction of pancreatic $\beta$ cells [1]. Over the past three decades, the number of people living with diabetes has increased more than double globally. Diabetes has now become a major public health issue across the entire world [2-4]. Moreover, diabetes and its complications have a significant economic impact on individuals, families, and countries [5]. The global prevalence of diabetes is estimated to be $9.3 \%$ (approximately 463 million people), with T2DM accounting for more than $90 \%$ of all diabetics $[6,7]$. Insulin resistance and long-term hyperglycemia will inevitably lead to changes in various metabolic and cellular functions, such as dyslipidemia, increased blood pressure, endothelial dysfunction, and increased platelet reactivity and oxidative stress. These factors can cause chronic inflammation, thereby damaging blood vessels and accelerating the occurrence and development of diabetic microvascular and macrovascular complications [8-12]. Although routine hypoglycemic drugs are widely used, these still fail to 
effectively prevent the progression of diabetes and may cause side effects such as gastrointestinal reactions (nausea, vomiting, and diarrhea), dizziness [13], and hypoglycemia [14]. Thus, the treatment of T2DM has become a significant hotspot for medical research, particularly with regard to developing new treatments for T2DM.

Traditional Chinese medicine (TCM) has a long history in the treatment of diabetes and has been associated with remarkable curative effects. TCM plays an important role in the management of diabetes in China [15] and is believed to relieve diabetes by comprehensively regulating the qi and blood balance in human body. As a representative Chinese patent medicine, YQP has been approved by the China Food and Drug Administration (CFDA) (approval number: Z51021085) for the treatment of diabetes and its complications. YQP comprises the following herbs: Pueraria montana var. Thomsonii (Benth.) (gě gèn), Trichosanthes kirilowii Maxim. (tiān huā fèn), Ophiopogon japonicus (Thunb.) Ker Gawl. (mài dōng), Rehmannia glutinosa (Gaertn.) DC. (di huáng), Schisandra chinensis (Turcz.) Baill. (wǔ wèi ž̀), and Glycyrrhiza glabra L. (gān căo). According to the basic theory of TCM, T2DM is triggered by yin deficiency. YQP has the efficacy of nourishing yin, moistening dryness, and promoting fluid, which can treat T2DM in essence. The composition and details of YQP are generalized in Figure 1 and Table 1.

Since its approval, YQP has become one of the most commonly used Chinese patent medicines to treat diabetes and its complications. The Guidelines for the Prevention and Treatment of Diabetes by Traditional Chinese Medicine (2011 Edition) issued by the Chinese Medical Association recommends YQP as the prescription for the treatment of diabetes [16]. Studies have shown that YQP can improve insulin sensitivity, regulate glucose and lipid metabolism, and improve macrovascular disease and microvascular disease in diabetic patients [17-19]. YQP has also been shown to protect endothelial cells, alleviate inflammatory responses, and reduce the serum levels of vascular endothelial growth factor (VEGF) [20-22]. An increasing number of clinical studies have reported that YQP may effectively improve the clinical symptoms and indicators of T2DM [23-26]. However, to the best of our knowledge, there has been no evaluation that has systematically analyzed the efficacy and safety of YQP and whether this drug represents an ideal form of alternative therapy. In the present study, we used evidence-based methods to evaluate the efficacy and safety of YQP for the treatment of T2DM. Our aim was to provide more robust scientific evidence for clinicians, researchers, and policy makers.

\section{Methods}

2.1. Database and Search Strategies. The protocol for this systematic review was registered in the International Prospective Register of Systematic Reviews (PROSPERO) with a registration number CRD42021261805.

This review was designed and performed in accordance with the guidelines of Preferred Reporting Items for Systematic Review and Meta-Analysis Protocols (PRISMA-P) 2015 [27]. All reviewers received relevant training to grasp the background, purpose, and process of the review.
We systematically searched 9 databases for specific keywords from inception to Oct 2021, including PubMed, Web of Science, the Cochrane Library, the China National Knowledge Infrastructure (CNKI), China Biology Medicine Disc (Sino Med), the Wan Fang Database, and the VIP information resource integration service platform (CQVIP). YQP (approval number: Z51021085) is a commonly used Chinese patent medicine for the treatment of diabetes in China. In order to avoid missing unpublished clinical trials for patent reasons, we additionally searched the patent database. A detailed retrieval of domestic and foreign patent information was carried out in Patent Search and Analysis of National Intellectual Property Administration (http://psssystem.cnipa.gov.cn/sipopublicsearch/portal/uiIndex.shtml). Google scholar was also carefully searched to find missing publications. We included all RCTs that were associated with YQP for T2DM without language limitation. The search terms were as follows: "Yuquan Pill," "Yuquan wan," "Yuquan," "Yu-Quan Pill," "yuquan pill," "Diabetes Mellitus," "Diabetes Insipidus," "Diet, Diabetic," "Prediabetic State," "Glycation End Products, Advanced," "Gastroparesis," and "Glucose Intolerance." Meanwhile, we also carefully studied the references of the relevant literature for more available studies.

2.2. Inclusion and Exclusion Criteria. Only randomized controlled trials (RCTs) that assessed the effects of YQP for T2DM were selected. Reviews, retrospective study, and animal experiments were excluded. For participants, we only included adult patients with a definite diagnosis of T2DM, without limitations relating to gender, regions, and ethnicity. According to the American Diabetes Association's diabetes guidelines [28], the diagnostic criteria for T2DM are as follows: fasting blood glucose $(\mathrm{FBG}) \geq 126 \mathrm{mg} / \mathrm{dL}(7.0 \mathrm{mmol} / \mathrm{L})$ or 2 -hour postprandial blood glucose $(2 \mathrm{hPG}) \geq 200 \mathrm{mg} / \mathrm{dL}(11.1 \mathrm{mmol} / \mathrm{L})$ during Oral glucose tolerance test (OGTT) or glycosylated hemoglobin $(\mathrm{HbAlc}) \geq 6.5 \%(48 \mathrm{mmol} / \mathrm{mol})$ or in a patient with classic symptoms of hyperglycemia or hyperglycemic crisis, a random plasma glucose $\geq 200 \mathrm{mg} / \mathrm{dL}$ (11.1 mmol/L). In terms of types of interventions, the treatment groups were treated with YQP, including pills, decoction, and granules, regardless of frequency and duration. The control group received conventional diabetes medicine or placebo treatment. It was worth mentioning that the studies that adopted multiple interventions or that YQP was not the primary intervention had been excluded. As this research aims to systematically evaluate the effects of YQP in the treatment of T2DM, the primary outcomes of the present study were FBG, 2hPG, and HbAlc. The secondary outcomes were total cholesterol (TC), c-reactive protein (CRP), and overall effective rate, while the safety was measured by adverse effects.

\subsection{Data Collection and Analysis}

2.3.1. Study Selection. Study selection was independently done by two investigators (JK and HY), based on the titles and abstracts to select for appropriate publications. EndNote V.X9 software was used for literature management. Any disagreements were submitted to a senior investigator (GX). 


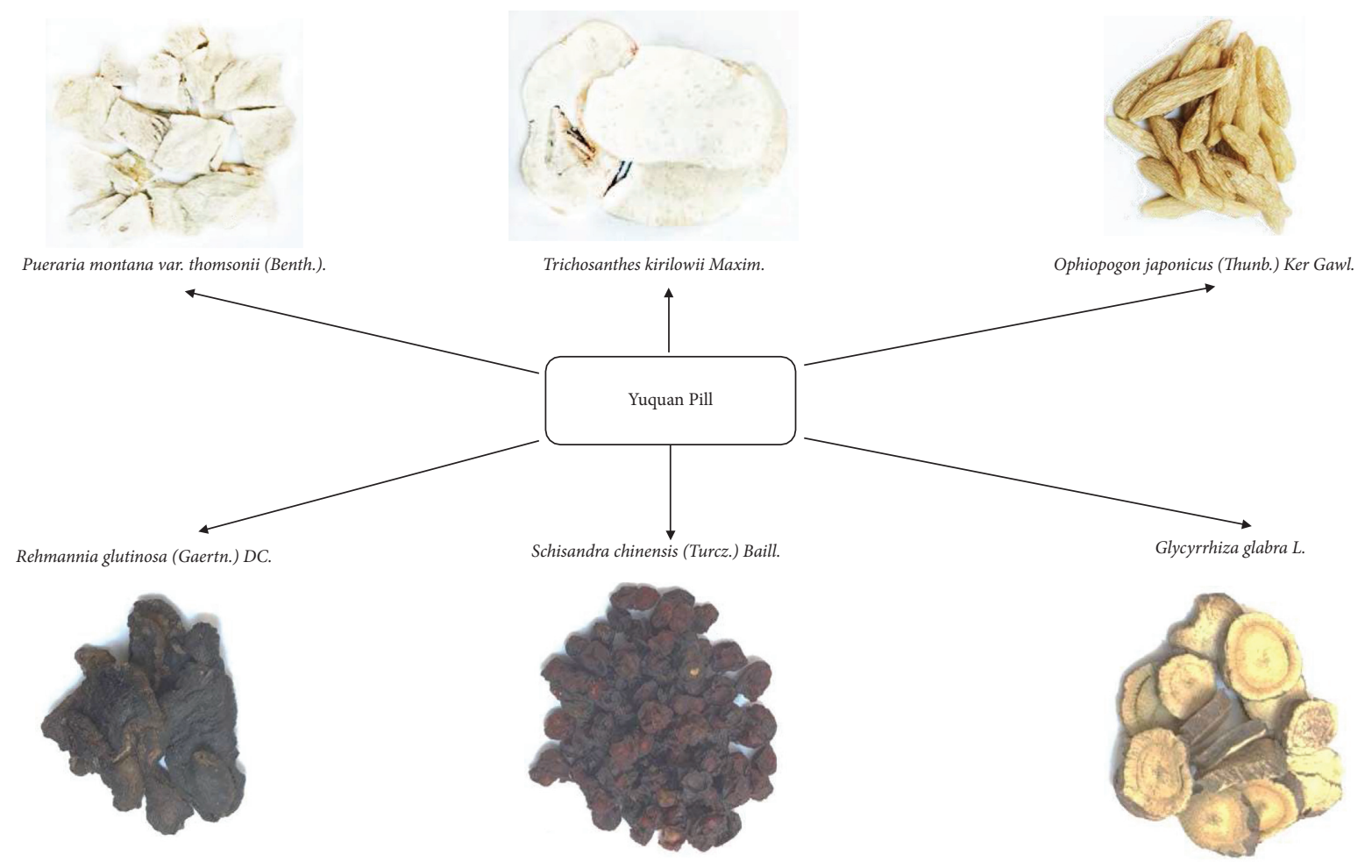

Figure 1: The composition of Yuquan Pill.

Table 1: Details of Yuquan Pill.

\begin{tabular}{|c|c|c|c|c|}
\hline Chinese herbs & Latin name & Family & Part of herbs & Function in Chinese medicine \\
\hline Ge Gen (gě gēn) & $\begin{array}{c}\text { Pueraria montana var. Thomsonii } \\
\text { (Benth.). }\end{array}$ & Fabaceae & Root & To promote fluid, relieve thirst, and clear heat \\
\hline $\begin{array}{l}\text { Tian Hua Fen (tiān } \\
\text { huā fẽn) }\end{array}$ & Trichosanthes kirilowii Maxim. & Cucurbitaceae & Root & To clear heat and promote fluid \\
\hline Mai Dong (mài dōng) & $\begin{array}{l}\text { Ophiopogon japonicus (Thunb.) } \\
\text { Ker Gawl. }\end{array}$ & Asparagaceae & Root & $\begin{array}{c}\text { To nourish yin, moisten lung, and promote } \\
\text { fluid }\end{array}$ \\
\hline Di Huang (dì huáng) & $\begin{array}{c}\text { Rehmannia glutinosa (Gaertn.) } \\
\text { DC. }\end{array}$ & Plantaginaceae & Root & To nourish yin, promote fluid, and clear heat \\
\hline $\begin{array}{l}\text { Wu Wei Zi (wǔ wèi } \\
\text { zĭ) }\end{array}$ & $\begin{array}{l}\text { Schisandra chinensis (Turcz.) } \\
\text { Baill. }\end{array}$ & Schisandraceae & Fructus & $\begin{array}{c}\text { To promote fluid and nourish lung and } \\
\text { kidney }\end{array}$ \\
\hline Gan Cao (gān căo) & Glycyrrhiza glabra L. & Fabaceae & $\begin{array}{l}\text { Root and } \\
\text { rhizome }\end{array}$ & $\begin{array}{c}\text { To replenish qi, tonify spleen, moisten lung, } \\
\text { and promote fluid }\end{array}$ \\
\hline
\end{tabular}

2.3.2. Data Extraction and Management. The following information was independently extracted by two reviewers (JK and GX): general information, including the first author, journal, publication time, and country; participant characteristics, such as sample size, gender, mean age, and duration of disease; interventions of treatment and control groups; outcomes including FBG, 2hPG, HbAlc, TC, CRP, and overall effective rate. The information was cross-checked by two investigators, and any disagreements were resolved by a third reviewer (SP).

2.3.3. Assessment of Risk of Bias. Two independent investigators (JK and GX) assessed the risk of bias in the light of the Cochrane Collaboration's Risk of Bias tool
[29]. The grades were rated as "low," "high," or "unclear" risk of bias, based on the following items: random sequence generation, allocation concealment, incomplete data, blinding, selective reporting, and other sources of bias. Any differences were discussed and resolved with a third researcher (HY).

2.3.4. Data Analysis. We used Review Manager (version 5.3) software to analyze all data to evaluate the effect of YQP on T2DM patients from the aspects of blood glucose, blood lipid, and so on. Continuous variables, including FBG, 2hPG, HbAlc, TC, and CRP, were evaluated by weighted mean differences (WMDs) and 95\% confidence intervals (CIs). Dichotomous data, such as overall effective rate and risk ratio 
(RR) with 95\% CI, was used to measure the treatment effect. When important data was incomplete in the reported literature, we contacted the authors by various means to get more relevant information.

2.3.5. Subgroup Analysis. The heterogeneity was assessed by the $I^{2}$ value. If the $I^{2}$ value exceeds $50 \%$, it means that there is significant statistical heterogeneity [30]. Subgroup analysis was constructed to explore the potential causes of heterogeneity. The subgroup analysis focused on the following factors: different ages ( $\geq 50 \mathrm{y}$ or $<50 \mathrm{y}$ ), different control groups (metformin or other treatments), durations of T2DM ( $\geq 10 y$ or $<10 y)$ or different regions, and so on.

2.3.6. Sensitivity Analysis. When the outcomes were unstable, sensitivity analysis was carried out by removing studies with high risk of bias and recalculating the pooled data to evaluate the robustness of merged results.

2.3.7. Assessment of Publication Bias. Due to insufficient included studies, there was no evaluation of publication bias conducted in this study.

\section{Results}

3.1. Literature Search. Figure 2 shows the process used to select studies for analysis. A total of 335 relevant literature articles were initially identified by our database searches; 168 publications were excluded due to duplicate findings. Of the remaining 167 articles, some were excluded because they failed to meet our specific inclusion criteria. For example, they were reviews or involved animal experiments, and finally there were 19 literatures left. Then, after carefully reading the full texts of these 19 articles, we removed nonRCTs [31, 32], RCTs without treating DM [33], and the articles lacking sufficient details on outcomes [34-39]. At last, 10 clinical trials [40-49] were included in the metaanalysis.

3.2. Characteristics of the Included Studies. A total of 871 patients were included in the 10 studies, 455 in treatment groups and 416 in control groups. The mean age of the patients described in these 10 articles ranged from $41.70 \pm 11.05$ years [43] to $69.30 \pm 5.35$ years [42]. The intervention measure used for all treatment groups was the administration of YQP in combination with conventional therapy. Of the 10 articles, 9 articles referred directly to T2DM [41-49], while one article referred specifically to diabetic nephropathy [40]; we included this latter article because diabetic nephropathy was a common complication of diabetes. All 10 studies were carried out in China and were published between 2005 and 2021. The shortest and longest treatment duration were 1 month $[42,49]$ and 3 months $[41,43,45,48]$, respectively. Table 2 shows the detailed characteristics of the 10 studies that underwent final analysis herein.
3.3. The Risk of Bias in the Analyzed Studies. We investigated the risk of bias for all the articles included in our analysis. All the study items were randomly divided into a YQP group and a control group. The randomization of treatments was not consistent when compared across the 10 articles; only one study [42] was classified as low risk of bias because it was randomized using a random number table; another study [48] did not include randomization and was therefore associated with a high risk of bias; the other 8 studies did not mention the specific randomization method used; the risk of bias for these papers was therefore determined as being 'unclear.' None of the RCTs reported allocation concealment. In terms of performance bias, none of the 10 articles included in this analysis reported the blinding of the participants or researchers. Therefore, we classified all 10 studies as having a high risk of bias in this domain. With regard to other biases, one study [40] did not report the treatment duration; therefore the risk was classified as being high. The complete and detailed analysis for the risk of bias is presented in Figures 3 and 4.

\subsection{Outcomes}

3.4.1. Fasting Blood Glucose. Nine studies involving 802 diabetic patients provided data on FBG before and after intervention between treatment and control groups [40-48]. Using fixed effects model, the results suggested that YQP plus conventional treatment might significantly reduce FBG in patients with T2DM $(\mathrm{WMD}=-0.83 ; 95 \%$ CI $[-1.01,-0.66], p<0.00001$; see Figure 5). And the heterogeneity was low $\left(\chi^{2}=15.63 ; p=0.05, \mathrm{I}^{2}=49 \%\right.$; see Figure 5$)$. In subgroup analysis, there was no significant difference between subgroups of different ages $(p=0.14)$ and different control treatments $(p=0.31)$ (Table 3, Supplementary Materials 1 and 2).

3.4.2. Two-Hour Postprandial Glucose. Eight studies (including 689 patients) evaluated the effect of YQP on $2 \mathrm{hPG}$ [42-49]. Results from pooled data analysis implied a significant decrease in $2 \mathrm{hPG}$ with low heterogeneity $(\mathrm{WMD}=-1.40 ; 95 \%$ CI $[-1.49,-1.31] ; p<0.00001$; heterogeneity: $p=0.19, \mathrm{I}^{2}=29 \%$, fixed effects model; see Figure 6). In subgroup analysis, there was no significant difference between subgroups of different ages $(p=0.19)$, different control treatments $(p=0.64)$, and different courses of treatment $(p=0.95)$ (Table 3, Supplementary Materials $3-5)$.

3.4.3. Glycosylated Hemoglobin. A total of 6 studies including 572 participants reported $\mathrm{HbAlc}$ levels [40, 41, 44-47]. According to the random effects model, the results showed that YQP combined with conventional treatment could reduce the HbAlc levels of T2DM $(\mathrm{WMD}=-0.87 ; 95 \%$ CI $[-1.26,-0.49] ; p<0.00001$; see Figure 7$)$. We found a significant heterogeneity among these researches $\left(\chi^{2}=22.42, p=0.0004\right.$, and $I^{2}=78 \%$; see Figure 7); therefore, subgroup analysis was performed. Subgroup 


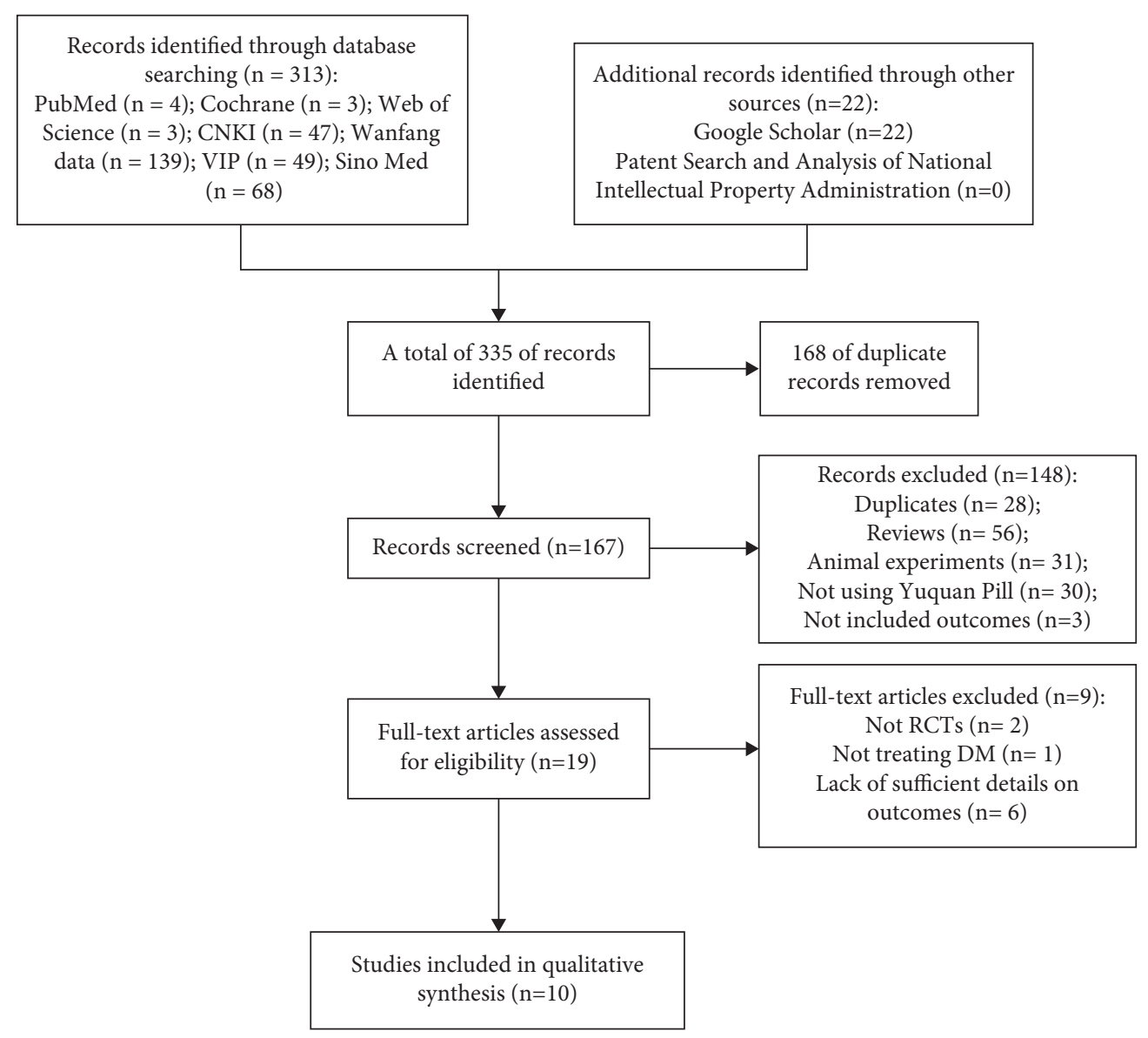

FIgURE 2: Flow diagram of studies selection process.

analyses according to different ages, control treatments, and durations of disease showed no significant difference in intervention effect between groups ( $p$ for interaction $=0.11$, 0.74 , and 0.26 , resp.), and the significant heterogeneity was still observed (Table 3, Supplementary Materials 6-8).

3.4.4. Total Cholesterol. Three studies involving 247 T2DM evaluated the effect of adding YQP to conventional treatment on TC levels $[45,48,49]$. The combination therapy might significantly reduce the TC levels in T2DM patients compared with control group (WMD $=-0.50 ; 95 \%$ CI $[-0.61,-0.39]$; $p<0.00001$, fixed effects model; see Figure 8) and with low heterogeneity $\left(\chi^{2}=1.65, p=0.44\right.$, and $\mathrm{I}^{2}=0 \%$; see Figure 8$)$. In subgroup analysis, there was no significant difference between subgroups of different ages $(p=0.20)$ and different courses of treatment $(p=0.97)$ (Table 3, Supplementary Materials 9-10).

3.4.5. C-Reactive Protein. Four studies explored CRP between treatment group and control group [41, 43-45]. All the studies involving 406 T2DM patients showed that YQP plus conventional treatment might significantly reduce CRP (WMD $=-0.58 ; 95 \%$ CI $[-0.88,-0.28] ; p=0.0002$, random effects model; see Figure 9). Significant heterogeneity was observed $\left(\chi^{2}=17.54, p=0.0005\right.$, and $\mathrm{I}^{2}=83 \%$; see Figure 9$)$. Subgroup analyses according to different ages, safety, and regions showed no significant difference between groups ( $p$ for interaction $=0.84,0.05$, and 0.81 , resp.) (Table 3, Supplementary Materials 11-13).

3.4.6. Overall Effective Rate. The overall effective rate was divided into significant effective, effective, and ineffective according to the degree of improvement of clinical symptoms and related indicators (mainly refers to blood glucose level, including FBG, $2 \mathrm{hPG}$, and HbA1c). Six researches that involved 600 patients mentioned overall effective rate as outcome [41, 43-47]. Since the absence of substantial heterogeneity $\left(\chi^{2}=2.70, p=0.75\right.$, and $I^{2}=0 \%$; see Figure 10$)$, we used the fixed effects model for statistical analysis. The results of the meta-analysis showed that YQP might result in a significant increase in overall effective rate compared with conventional treatment $(\mathrm{RR}=1.21 ; 95 \%$ CI $[1.12,1.31]$; $p<0.00001$; see Figure 10). Subgroup analyses by different ages, control treatments, courses of treatment, and regions showed no significant difference in effect size ( $p$ for interaction $=0.90,0.79,0.27$, and 0.50, resp.) (Table 3, Supplementary Materials 14-17).

3.4.7. Adverse Effects. Adverse effects were reported in 7 of 10 studies. Three of them reported that no adverse effect was found [42, 43, 48]. Four studies [41, 44, 45, 49] 


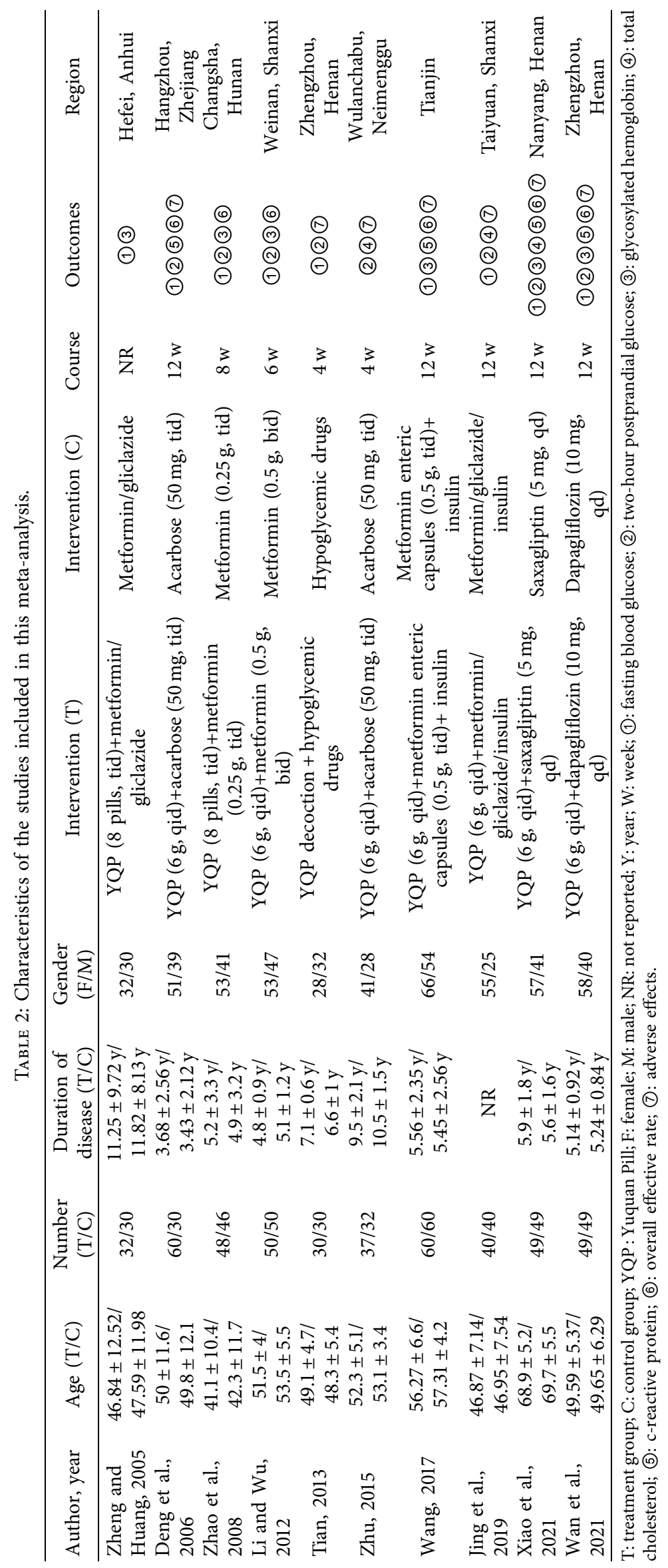




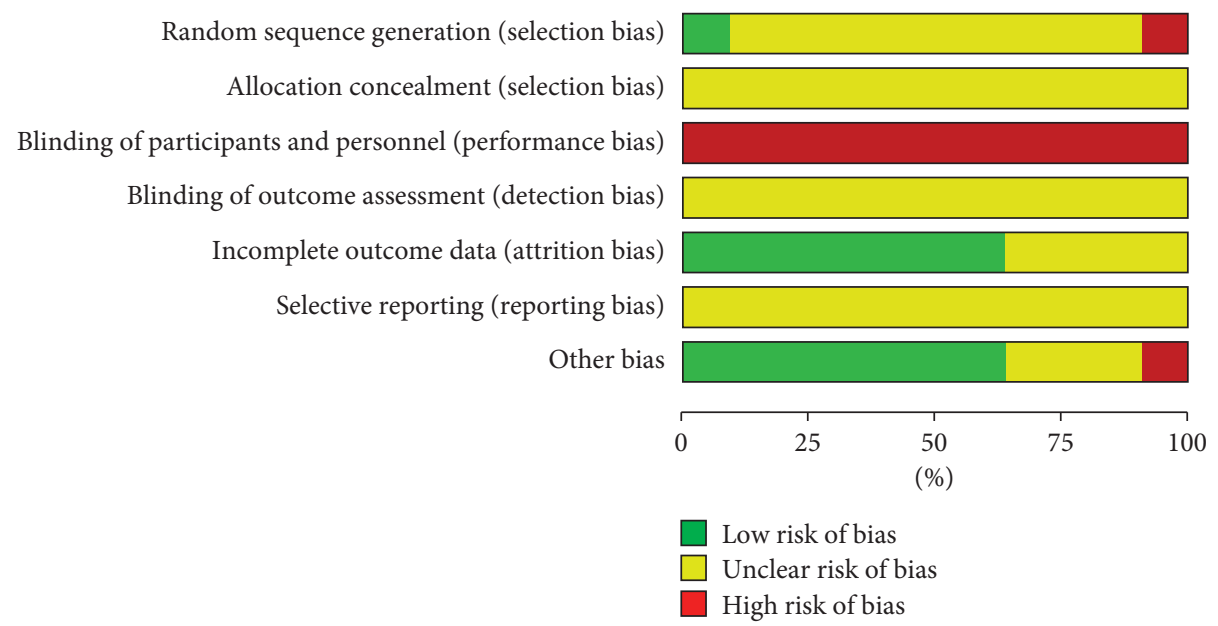

FIgURE 3: Risk of bias graph.

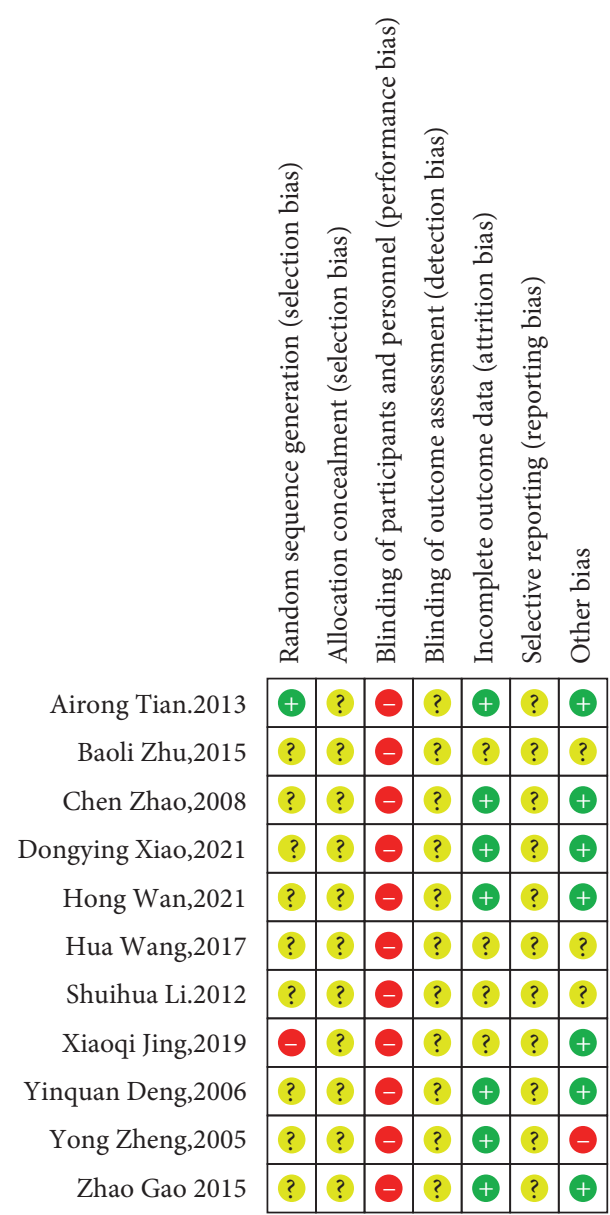

FIgURE 4: Risk of bias summary.

reported the occurrence of general adverse effects. The most common adverse effect among these studies was abdominal discomfort [41, 44, 45, 49]. Headache, dizziness, nausea, and hypoglycemia were also reported to occur in the researches. No adverse effects were reported in the remaining studies.

\section{Discussion}

4.1. Main Results. With the continuous development and wide application of evidence-based medicine, systematic reviews and meta-analyses have become a recognized and widely accepted research method. Such studies can facilitate the evaluation of clinical evidence and serve as a strong foundation for evidencebased decision making [50]. However, until now, there has been no specific evaluation of the clinical evidence related to the use of YQP for the treatment of T2DM.

A total of 335 relevant articles were retrieved in our initial database searches. Ten of these articles were included in our final meta-analysis after eliminating duplicate articles and applying our specific exclusion criteria. Data analysis demonstrated that, compared to conventional treatment alone, the coadministration of YQP and conventional medicine may be more effective with regard to exerting effects on FBG, 2hPG, $\mathrm{HbA1c}$, TC, and CRP; there was also evidence for an improvement in the overall effective rate. Our analyses also showed that there was evidence for improvements in glucose and lipid metabolism and the inflammation associated with T2DM, at least to some extent. Next, we divided the participants into subgroups according to their specific characteristics (such as age and region) and differences with regard to control treatment and the duration of treatment. Comprehensive subgroup analysis was then performed on the basis of these variables to explain or reduce the observed levels of heterogeneity. Although a series of subgroup analyses were conducted in the present study, we identified high levels of heterogeneity with regard to $\mathrm{HbAlc}$ and CRP data. The combination of effect sizes using a random effects model did not reduce the observed heterogeneity or identify the source of such heterogeneity. It was considered that it might be related to the difference in origin, quality, and water content of the Chinese herbs [51,52] and further analysis could not be conducted due to no specific details in the article.

When considering the statistical heterogeneity of metaanalysis, it is important to consider two different components: clinical heterogeneity and methodological heterogeneity. In our meta-analysis, it is possible that different T2DM participants 


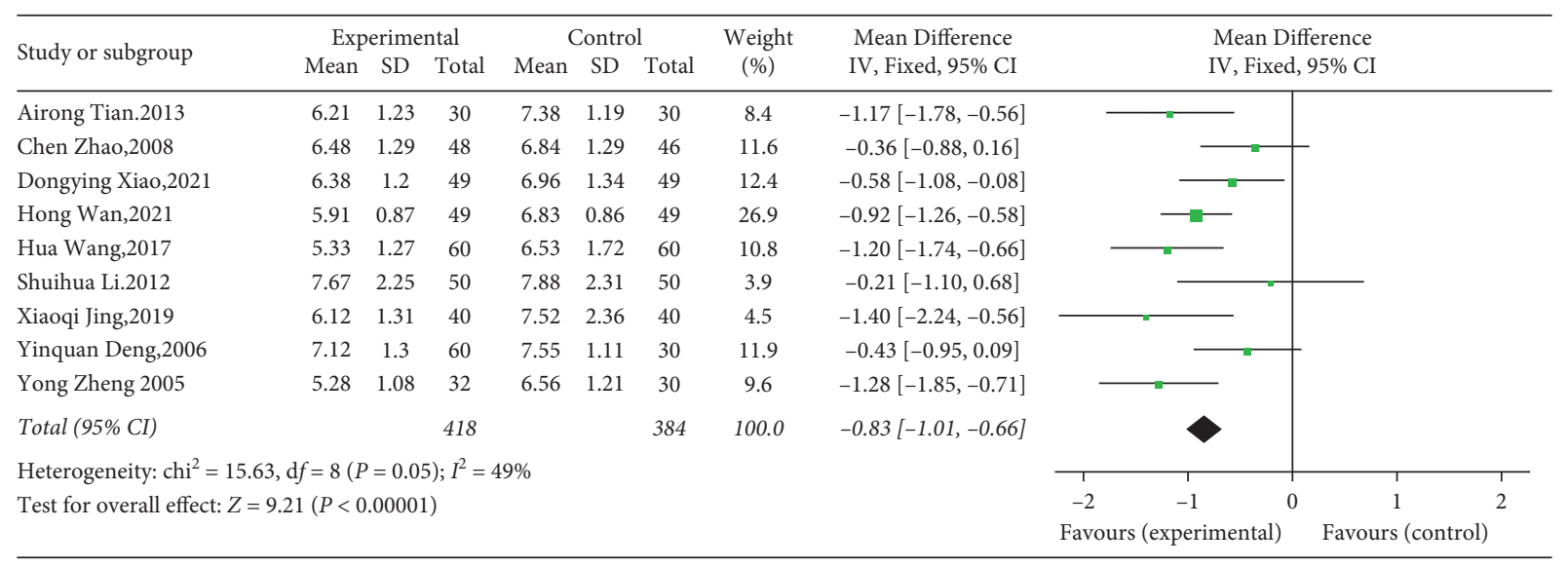

FIgURE 5: Forest plot for FBG.

TABle 3: Subgroup analysis for outcomes.

\begin{tabular}{|c|c|c|c|c|c|}
\hline & Number of comparisons & Results & $p$ value for overall effect & $I^{2}$ & $\begin{array}{c}p \text { value for } \\
\text { subgroup difference }\end{array}$ \\
\hline$\overline{\text { FBG }}$ & & WMD (95\%CI) & & & \\
\hline All comparisons & 9 & $-0.84[-1.10,-0.58]$ & $<0.00001$ & $49 \%$ & \\
\hline Age & & & & & 0.14 \\
\hline$<50 y$ & 5 & $-0.94[-1.17,-0.71]$ & $<0.00001$ & $49 \%$ & \\
\hline$\geq 50 y$ & 4 & $-0.67[-0.95,-0.38]$ & $<0.00001$ & $47 \%$ & \\
\hline Different control treatment & & & & & 0.31 \\
\hline Metformin & 3 & $-0.68[-1.03,-0.34]$ & 0.0001 & $67 \%$ & \\
\hline Other treatments & 6 & $-0.89[-1.10,-0.68]$ & $<0.00001$ & $42 \%$ & \\
\hline \multicolumn{6}{|l|}{$2 \mathrm{hPG}$} \\
\hline All comparisons & 8 & $-1.39[-1.58,-1.20]$ & $<0.00001$ & $29 \%$ & \\
\hline Age & & & & & 0.19 \\
\hline$<50 y$ & 4 & $-1.60[-1.91,-1.29]$ & $<0.00001$ & $0 \%$ & \\
\hline$\geq 50 y$ & 4 & $-1.38[-1.47,-1.29]$ & $<0.00001$ & $43 \%$ & \\
\hline Different control treatment & & & & & 0.64 \\
\hline Metformin & 2 & $-1.53[-1.93,-1.13]$ & $<0.00001$ & $0 \%$ & \\
\hline Acarbose & 2 & $-1.38[-1.48,-1.29]$ & $<0.00001$ & $73 \%$ & \\
\hline Other treatments & 4 & $-1.49[-1.79,-1.19]$ & $<0.00001$ & $43 \%$ & \\
\hline Course of treatment & & & & & 0.95 \\
\hline$<8 w$ & 3 & $-1.39[-1.49,-1.30]$ & $<0.00001$ & $0 \%$ & \\
\hline$\geq 8 \mathrm{w}$ & 5 & $-1.38[-1.65,-1.12]$ & $<0.00001$ & $56 \%$ & \\
\hline \multicolumn{6}{|l|}{ HbAlc } \\
\hline All comparisons & 6 & $-0.87[-1.26,-0.49]$ & $<0.00001$ & $78 \%$ & \\
\hline Age & & & & & 0.11 \\
\hline$<50 y$ & 3 & $-1.09[-1.38,-0.80]$ & $<0.00001$ & $10 \%$ & \\
\hline$\geq 50 y$ & 3 & $-0.61[-1.12,-0.11]$ & 0.02 & $78 \%$ & \\
\hline Different control treatment & & & & & 0.74 \\
\hline Metformin & 3 & $-0.84[-1.31,-0.37]$ & 0.0005 & $74 \%$ & \\
\hline Other treatments & 3 & $-1.01[-1.86,-0.15]$ & 0.02 & $83 \%$ & \\
\hline Duration of disease & & & & & 0.26 \\
\hline$<10 y$ & 5 & $-0.82[-1.22,-0.42]$ & 0.0004 & $81 \%$ & \\
\hline$\geq 10 y$ & 1 & $-1.60[-2.91,-0.29]$ & 0.02 & NA & \\
\hline \multicolumn{6}{|l|}{ TC } \\
\hline All comparisons & 3 & $-0.50[-0.61,-0.39]$ & $<0.00001$ & $0 \%$ & \\
\hline Age & & & & & 0.20 \\
\hline$<50 y$ & 1 & $-1.02[-1.83,-0.21]$ & 0.01 & NA & \\
\hline$\geq 50 y$ & 2 & $-0.49[-0.60,-0.38]$ & $<0.00001$ & $0 \%$ & \\
\hline Course of treatment & & & & & 0.97 \\
\hline$<8 w$ & 1 & $-0.50[-0.68,-0.32]$ & $<0.00001$ & NA & \\
\hline$\geq 8 \mathrm{w}$ & 2 & $-0.50[-0.64,-0.36]$ & $<0.00001$ & $40 \%$ & \\
\hline \multicolumn{6}{|l|}{ CRP } \\
\hline All comparisons & 4 & $-0.58[-0.88,-0.28]$ & 0.0005 & $83 \%$ & \\
\hline
\end{tabular}


TABLE 3: Continued.

\begin{tabular}{|c|c|c|c|c|c|}
\hline & Number of comparisons & Results & $p$ value for overall effect & $I^{2}$ & $\begin{array}{c}p \text { value for } \\
\text { subgroup difference }\end{array}$ \\
\hline Age & & & & & 0.84 \\
\hline$<50 \mathrm{y}$ & 1 & $-0.55[-0.69,-0.41]$ & $<0.00001$ & NA & \\
\hline$\geq 50 \mathrm{y}$ & 3 & $-0.61[-1.18,-0.05]$ & 0.03 & $88 \%$ & \\
\hline Safety & & & & & 0.05 \\
\hline No adverse effects & 1 & $-1.13[-1.49,-0.77]$ & $<0.00001$ & NA & \\
\hline Adverse effects occurring & 3 & $-0.62[-0.97,-0.26]$ & 0.0007 & $89 \%$ & \\
\hline Region & & & & & 0.81 \\
\hline Henan province & 2 & $-0.81[-1.38,-0.25]$ & 0.005 & $88 \%$ & \\
\hline Other provinces & 2 & $-0.69[-1.52,0.14]$ & 0.10 & $94 \%$ & \\
\hline Overall effective rate & & $\mathrm{RR}(95 \% \mathrm{CI})$ & & & \\
\hline All comparisons & 6 & $1.21[1.12,1.31]$ & $<0.00001$ & $0 \%$ & \\
\hline Age & & & & & 0.90 \\
\hline$<50 \mathrm{y}$ & 2 & $1.22[1.08,1.38]$ & 0.001 & $0 \%$ & \\
\hline$\geq 50 \mathrm{y}$ & 4 & $1.21[1.09,1.34]$ & 0.0002 & $0 \%$ & \\
\hline Different control treatment & & & & & 0.79 \\
\hline Metformin & 3 & $1.20[1.08,1.34]$ & 0.001 & $0 \%$ & \\
\hline Other treatments & 3 & $1.23[1.10,1.37]$ & 0.0003 & $0 \%$ & \\
\hline Course of treatment & & & & & 0.27 \\
\hline$<8 \mathrm{w}$ & 1 & $1.10[0.92,1.33]$ & 0.30 & NA & \\
\hline$\geq 8 \mathrm{w}$ & 5 & $1.24[1.14,1.35]$ & $<0.00001$ & $0 \%$ & \\
\hline Region & & & & & 0.50 \\
\hline Henan province & 2 & $1.18[1.06,1.30]$ & 0.002 & $0 \%$ & \\
\hline Other provinces & 4 & $1.24[1.11,1.38]$ & 0.0001 & $0 \%$ & \\
\hline
\end{tabular}

FBG, fasting blood glucose; 2hPG, two-hour postprandial glucose; HbA1c, glycosylated hemoglobin; TC, total cholesterol; CRP, c-reactive protein; Y, year; W, week.

and different intervention measures may lead to a certain extent of clinical heterogeneity. Methodological heterogeneity may be caused by differences in trial design and poor methodological quality, such as the inappropriate use of blinding methods and hidden differences in allocation. In the present study, our subgroup analysis was based on a range of factors, including age, course of disease, intervention measures, and the treatment duration; these analyses involved post hoc analysis, thus reducing the reliability of our subgroup analysis.

4.2. Certainty of the Evidence. We used GRADEpro software to assess the certainty of the evidence that was analyzed in this study. Figure 11 showed that the FBG, 2hPG, and the effective rate had a moderate quality of evidence, while HbAlc and TC in RCTs had a low certainty of evidence, and CRP had a very low certainty of evidence. The observed reduction in the certainty of evidence was mainly attributed to the high risk of bias in the studies analyzed, inconsistency between the included studies, and the imprecision of the findings. Specifically, this is due to the low methodological quality of the included studies, the high heterogeneity of some studies, and the small sample size of some studies. The poor methodological quality of some of the included studies was indicated by unclear randomization allocation and blinding strategies. As a direct result of these factors, our current findings should be considered cautiously for clinical practice. Additional and more standardized RCTs are now needed to fully validate the effects of YQP on T2DM.
4.3. Strengths and Limitations. Our study has several advantages. For example, this is the first systematic review to investigate the efficacy and safety of YQP for the treatment of T2DM. Furthermore, we used a wide range of search terms to conduct a comprehensive and systematic search of established national and international databases. When missing or unclear data were evident, we actively contacted the authors to obtain relevant information. Secondly, in order to provide a comprehensive description of the use of YQP in the treatment of T2DM, this study was conducted in strict accordance with established methodology for systematic reviews. The results were carefully interpreted to ensure accuracy and avoid misleading conclusions. Thirdly, this systematic review and meta-analysis described and evaluated the present clinical trials on YQP for T2DM, filling the blank in existing knowledge. We found that, compared with conventional treatment, the combined use of YQP and conventional medicine could improve glucose and lipid metabolism and inflammation, associated with T2DM. The results of this study provide new treatment options for T2DM. YQP may improve the inflammatory condition of diabetes, which is the pathological basis and key factor of multiple complications of diabetes. It has farreaching influence, extensive research prospects, and important research significance, and it is worth further investigation. Although our current research is limited, we believe that, with the continuous development and promotion of traditional Chinese medicine, the importance of YQP for T2DM will become increasingly prominent. We hope that our study may provide new directions, ideas, and methods for the study of T2DM. 


\begin{tabular}{|c|c|c|c|c|c|c|c|c|c|c|c|c|c|}
\hline \multirow{3}{*}{$\begin{array}{l}\text { Study or subgroup } \\
\text { Airong Tian.2013 }\end{array}$} & \multicolumn{3}{|c|}{ Experimental } & \multicolumn{3}{|c|}{ Control } & \multirow{3}{*}{$\begin{array}{c}\begin{array}{c}\text { Weight } \\
(\%)\end{array} \\
1.6\end{array}$} & \multirow{3}{*}{$\begin{array}{c}\text { Mean Difference } \\
\text { IV, Fixed, 95\% CI } \\
-1.18[-1.88,-0.48]\end{array}$} & \multirow{2}{*}{\multicolumn{5}{|c|}{$\begin{array}{l}\text { Mean Difference } \\
\text { IV, Fixed, 95\% CI }\end{array}$}} \\
\hline & \multirow{2}{*}{$\frac{\text { Mean }}{8.08}$} & \multirow{2}{*}{$\frac{\mathrm{SD}}{1.36}$} & \multirow{2}{*}{$\begin{array}{c}\text { Total } \\
30\end{array}$} & \multirow{2}{*}{$\begin{array}{c}\text { Mean } \\
9.26\end{array}$} & \multirow{2}{*}{$\begin{array}{c}\mathrm{SD} \\
1.41\end{array}$} & \multirow{2}{*}{$\frac{\text { Total }}{30}$} & & & & & & & \\
\hline & & & & & & & & & & & & & \\
\hline Baoli Zhu,2015 & 8.1 & 0.26 & 37 & 9.5 & 0.13 & 32 & 84.2 & $-1.40[-1.50,-1.30]$ & & & & & \\
\hline Chen Zhao,2008 & 8.13 & 1.69 & 48 & 9.62 & 2.13 & 46 & 1.3 & $-1.49[-2.27,-0.71]$ & & & & & \\
\hline Dongying Xiao,2021 & 9.79 & 1.53 & 49 & 10.83 & 1.68 & 49 & 1.9 & $-1.04[-1.68,-0.40]$ & & & & & \\
\hline Hong Wan,2021 & 7.11 & 0.82 & 49 & 8.94 & 1.26 & 49 & 4.3 & $-1.83[-2.25,-1.41]$ & & & & & \\
\hline Shuihua Li.2012 & 11.22 & 1.13 & 50 & 12.77 & 1.24 & 50 & 3.5 & $-1.55[-2.02,-1.08]$ & & & & & \\
\hline Xiaoqi Jing,2019 & 7.56 & 1.63 & 40 & 8.87 & 2.96 & 40 & 0.7 & $-1.31[-2.36,-0.26]$ & & & & & \\
\hline Yinquan Deng,2006 & 8.3 & 1.06 & 60 & 9.16 & 1.32 & 30 & 2.6 & $-0.86[-1.40,-0.32]$ & & & & & \\
\hline Total (95\% CI) & & & 363 & & & 326 & 100.0 & $-1.40[-1.49,-1.31]$ & & & & & \\
\hline Heterogeneity: chi $^{2}=$ & $=7(P$ & $=0.19$ & $; I^{2}=2$ & & & & & & 1 & & & 1 & T \\
\hline Test for overall effect: & $44(P<$ & 0.000 & & & & & & & -2 & -1 & 0 & 1 & 2 \\
\hline & & & & & & & & & Favou & perim & & Favours & \\
\hline
\end{tabular}

Figure 6: Forest plot for 2hPG.

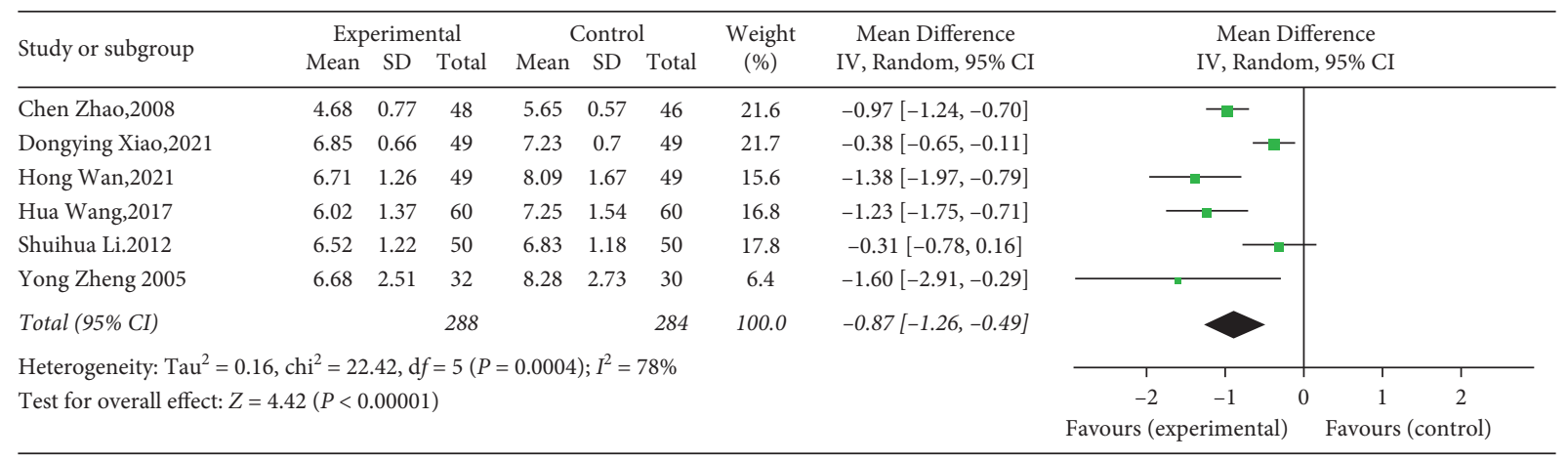

Figure 7: Forest plot for HbAlc.

\begin{tabular}{|c|c|c|c|c|c|c|c|c|c|c|c|c|}
\hline \multirow{3}{*}{$\begin{array}{l}\text { Study or subgroup } \\
\text { Baoli Zhu,2015 }\end{array}$} & \multicolumn{3}{|c|}{ Experimental } & \multicolumn{3}{|c|}{ Control } & \multirow{3}{*}{$\begin{array}{c}\begin{array}{c}\text { Weight } \\
(\%)\end{array} \\
36.6\end{array}$} & \multirow{3}{*}{$\begin{array}{c}\text { Mean Difference } \\
\text { IV, Fixed, 95\% CI } \\
-0.50[-0.68,-0.32]\end{array}$} & \multirow{2}{*}{\multicolumn{4}{|c|}{$\begin{array}{l}\text { Mean Difference } \\
\text { IV, Fixed, 95\% CI }\end{array}$}} \\
\hline & \multirow{2}{*}{$\frac{\text { Mean }}{3.8}$} & \multirow{2}{*}{$\frac{S D}{0.28}$} & \multirow{2}{*}{$\frac{\text { Total }}{37}$} & \multirow{2}{*}{$\begin{array}{c}\text { Mean } \\
4.3\end{array}$} & \multirow{2}{*}{$\frac{S D}{0.46}$} & \multirow{2}{*}{$\frac{\text { Total }}{32}$} & & & & & & \\
\hline & & & & & & & & & & - & & \\
\hline Dongying Xiao,2021 & 4.12 & 0.32 & 49 & 4.6 & 0.39 & 49 & 61.5 & $-0.48[-0.62,-0.34]$ & & 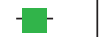 & & \\
\hline Xiaoqi Jing,2019 & 4.85 & 1.21 & 40 & 5.87 & 2.32 & 40 & 1.9 & $-1.02[-1.83,-0.21]$ & & & & \\
\hline Total (95\% CI) & & & 126 & & & 121 & 100.0 & $-0.50[-0.61,-0.39]$ & & & & \\
\hline \multicolumn{9}{|c|}{ Heterogeneity: chi $^{2}=1.65, \mathrm{~d} f=2(P=0.44) ; I^{2}=0 \%$} & $T$ & $T$ & $T$ & $T$ \\
\hline \multirow{2}{*}{\multicolumn{9}{|c|}{ Test for overall effect: $Z=8.80(P<0.00001)$}} & -1 & -0.5 & 0.5 & 1 \\
\hline & & & & & & & & & \multicolumn{4}{|c|}{ Favours (experimental) Favours (control) } \\
\hline
\end{tabular}

Figure 8: Forest plot for TC.

\begin{tabular}{|c|c|c|c|c|c|c|c|c|c|c|c|}
\hline \multirow{3}{*}{$\begin{array}{l}\text { Study or subgroup } \\
\text { Dongying Xiao,2021 }\end{array}$} & \multicolumn{3}{|c|}{ Experimental } & \multicolumn{3}{|c|}{ Control } & \multirow{3}{*}{$\begin{array}{c}\begin{array}{c}\text { Weight } \\
(\%)\end{array} \\
22.4\end{array}$} & \multirow{3}{*}{$\begin{array}{c}\text { Mean Difference } \\
\text { IV, Random, 95\% CI } \\
-1.13[-1.49,-0.77]\end{array}$} & \multirow{2}{*}{\multicolumn{3}{|c|}{$\begin{array}{c}\text { Mean Difference } \\
\text { IV, Random, 95\% CI }\end{array}$}} \\
\hline & Mean & $\mathrm{SD}$ & Total & Mean & SD & Total & & & & & \\
\hline & 2.26 & 0.81 & 49 & 3.39 & 1.02 & 49 & & & $\longrightarrow$ & & \\
\hline Hong Wan,2021 & 1.38 & 0.37 & 49 & 1.93 & 0.36 & 49 & 30.9 & $-0.55[-0.69,-0.41]$ & & & \\
\hline Hua Wang,2017 & 0.79 & 0.58 & 60 & 1.07 & 0.43 & 60 & 29.6 & $-0.28[-0.46,-0.10]$ & & $\longrightarrow-$ & \\
\hline Yinquan Deng,2006 & 6.87 & 1.15 & 60 & 7.31 & 1.18 & 30 & 17.0 & $-0.44[-0.95,0.07]$ & & - - & \\
\hline Total (95\% CI) & & & 218 & & & 188 & 100.0 & $-0.58[-0.88,-0.28]$ & & & \\
\hline \multicolumn{9}{|c|}{ Heterogeneity: $\mathrm{Tau}^{2}=0.07, \mathrm{chi}^{2}=17.54, \mathrm{~d} f=3(P=0.0005) ; I^{2}=83 \%$} & & & \\
\hline \multirow{2}{*}{\multicolumn{9}{|c|}{ Test for overall effect: $Z=3.76(P=0.0002)$}} & -1 & -0.5 & 0.5 \\
\hline & & & & & & & & & Favours (exp & erimental) & Favours (control) \\
\hline
\end{tabular}

Figure 9: Forest plot for CRP.

Although we made every effort to be rigorous and accurate in our research process, some limitations should be taken into account. First, the number of studies included in this meta-analysis was small and of low quality; these factors led to a low degree of certainty in terms of evidence. Consequently, our results should be interpreted with 


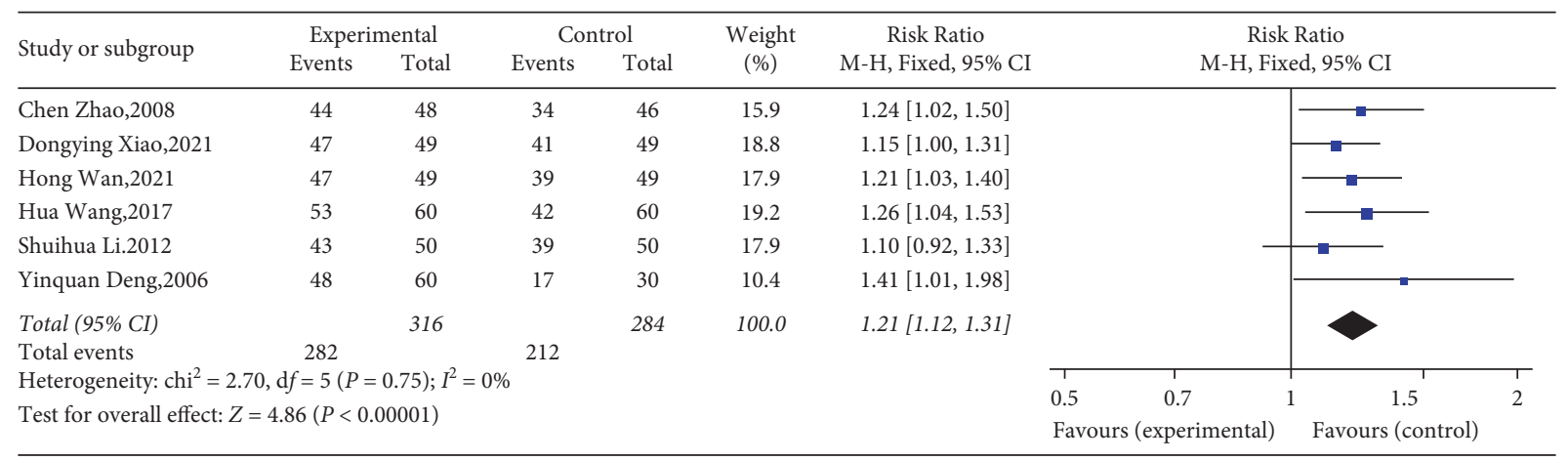

FIgURE 10: Forest plot for overall effective rate.

\begin{tabular}{|c|c|c|c|c|c|c|c|c|c|c|c|c|}
\hline \multicolumn{7}{|c|}{ Certainty assessment } & \multicolumn{2}{|c|}{ No of studies } & \multicolumn{2}{|c|}{ Effect } & \multirow{2}{*}{ Certainty } & \multirow{2}{*}{ Importance } \\
\hline $\begin{array}{l}\text { No of } \\
\text { studies }\end{array}$ & $\begin{array}{l}\text { Study } \\
\text { design }\end{array}$ & $\begin{array}{l}\text { Risk of } \\
\text { bias }\end{array}$ & Inconsistency & Indirectness & Imprecision & $\begin{array}{c}\text { Other } \\
\text { considerations }\end{array}$ & $\begin{array}{c}\text { Yuquan } \\
\text { pill }\end{array}$ & $\begin{array}{c}\text { Control } \\
\text { treatment }\end{array}$ & $\begin{array}{c}\text { Relative } \\
(95 \% \mathrm{CI})\end{array}$ & $\begin{array}{l}\text { Absolute } \\
(95 \% \text { CI })\end{array}$ & & \\
\hline \multicolumn{13}{|c|}{ Fasting blood glucose } \\
\hline 9 & $\begin{array}{l}\text { randomised } \\
\text { trials }\end{array}$ & serious $^{\mathrm{a}}$ & not serious & not serious & not serious & none & 418 & 384 & - & $\begin{array}{c}\text { MD } 0.84 \\
\text { lower } \\
(1.1 \\
\text { lower to } \\
0.58 \text { lower) }\end{array}$ & $\begin{array}{c}\oplus \oplus \oplus O \\
\text { MODERATE }\end{array}$ & CRITICAL \\
\hline \multicolumn{13}{|c|}{ Two-hour postprandial glucose } \\
\hline 8 & $\begin{array}{l}\text { randomised } \\
\text { trials }\end{array}$ & serious $^{\mathrm{a}}$ & not serious & not serious & not serious & none & 363 & 326 & - & $\begin{array}{c}\text { MD } 1.39 \\
\text { lower } \\
(1.58 \\
\text { lower to } \\
1.2 \text { lower) }\end{array}$ & $\begin{array}{c}\oplus \oplus \oplus \circ \\
\text { MODERATE }\end{array}$ & CRITICAL \\
\hline \multicolumn{13}{|c|}{ Glycosylated hemoglobin } \\
\hline 6 & $\begin{array}{l}\text { randomised } \\
\text { trials }\end{array}$ & serious $^{\mathrm{a}}$ & serious $^{\mathrm{b}}$ & not serious & not serious & none & 288 & 284 & - & $\begin{array}{c}\text { MD 0.87 } \\
\text { lower } \\
(1.26 \\
\text { lower to } \\
0.49 \text { lower) }\end{array}$ & $\begin{array}{l}\oplus \oplus \circ O \\
\text { LOW }\end{array}$ & CRITICAL \\
\hline \multicolumn{13}{|c|}{ Total cholesterol } \\
\hline 3 & $\begin{array}{l}\text { randomised } \\
\text { trials }\end{array}$ & serious $^{\mathrm{a}}$ & not serious & not serious & serious $^{c}$ & none & 126 & 121 & - & $\begin{array}{c}\text { MD } 0.5 \\
\text { lower } \\
(0.61 \\
\text { lower to } \\
0.39 \text { lower })\end{array}$ & $\begin{array}{l}\oplus \oplus \circ O \\
\text { LOW }\end{array}$ & IMPORTANT \\
\hline \multicolumn{13}{|c|}{ C-reactive protein } \\
\hline 4 & $\begin{array}{l}\text { randomised } \\
\text { trials }\end{array}$ & serious $^{\mathrm{a}}$ & serious $^{\mathrm{b}}$ & not serious & serious $^{c}$ & none & 218 & 188 & - & $\begin{array}{c}\text { MD } 0.58 \\
\text { lower } \\
(0.88 \\
\text { lower to } \\
0.28 \text { lower) }\end{array}$ & $\begin{array}{c}\oplus O 0 O \\
\text { VERY LOW }\end{array}$ & IMPORTANT \\
\hline \multicolumn{13}{|c|}{ Effective rate } \\
\hline 6 & $\begin{array}{l}\text { randomised } \\
\text { trials }\end{array}$ & serious $^{\mathrm{a}}$ & not serious & not serious & not serious & none & $\begin{array}{l}282 / 316 \\
(89.2 \%)\end{array}$ & $\begin{array}{l}212 / 284 \\
(74.6 \%)\end{array}$ & $\begin{array}{l}\text { RR } 1.21 \\
\text { (1.12 to } \\
1.31)\end{array}$ & $\begin{array}{c}157 \text { more } \\
\text { per } 1,000 \\
\text { (from } 90 \\
\text { more to } \\
231 \text { more) }\end{array}$ & $\begin{array}{c}\oplus \oplus \oplus O \\
\text { MODERATE }\end{array}$ & IMPORTANT \\
\hline
\end{tabular}

FIGURE 11: Certainty of evidence: Yuquan Pill compared to control treatment for T2DM. CI, confidence interval; MD, mean difference; RR, risk ratio. ${ }^{a}$ Randomization allocation and the blinding are unclear in articles. ${ }^{b}$ There is serious heterogeneity among the studies included in the analysis of this outcome. ${ }^{c}$ Results are imprecise since the study included relatively few studies and few patients.

caution. Secondly, there were some defects in the included articles with regard to RCT design. Certain methodologies related to random sequence generation, the allocation concealment, and blinding were generally poor. Only one study [42] clearly reported the generation of random sequences. Furthermore, none of the RCTs involved allocation concealment or the blinding of participants or researchers. This may have led to the overestimation of efficacy. Thirdly, since patients were only recruited from Chinese hospitals, our study may not be globally representative and lacks clinical applicability. Whether YQP can be applied to other ethnic groups remains to be elucidated.
In addition, the safety of YQP remains unclear because some studies did not report adverse events; thus, adverse events could not be systematically collated and analyzed. In subgroup analyses, the cutoff points for age and duration of disease are mainly based on related studies, and more biological basis is needed. Although we performed subgroup analyses for each outcome, the source of heterogeneity was not fully identified. Due to the limited number of studies included in this meta-analysis, we were unable to conduct meta-regression analysis to further explore the source of heterogeneity. Furthermore, we were unable to apply funnel plots to evaluate publication bias. 


\section{Conclusion}

In conclusion, this systematic review and meta-analysis evaluates the efficacy and safety of YQP on T2DM for the first time. We showed that, compared with conventional treatment, the combined administration of YQP and conventional medicine may improve glucose and lipid metabolism and the inflammatory conditions in patients with T2DM. However, due to the poor quality of these studies, the evidence remains very uncertain. Therefore, our results should be interpreted with caution and applied cautiously in clinical practice. In the future, more multicenter, large-scale, and high-quality RCTs will be needed to fully determine the clinical efficacy and safety of YQP for the treatment of T2DM.

\section{Abbreviations}

2hPG: 2-hour postprandial glucose

CFDA: China Food and Drug Administration

CIs: $\quad$ Confidence intervals

CNKI: China National Knowledge Infrastructure

CQVIP: VIP information resource integration service platform

CRP: c-Reactive protein

GRADE: Grading of recommendations assessment, development, and evaluation

HbA1c: Glycated hemoglobin

FBG: $\quad$ Fasting blood glucose

OGTT: Oral glucose tolerance test

PRISMA- Preferred reporting items for systematic review $P: \quad$ and meta-analysis protocols

RCTs: $\quad$ Randomized controlled trials

T2DM: Type 2 diabetes mellitus

TC: $\quad$ Total cholesterol

RR: $\quad$ Risk ratio

TCM: Traditional Chinese medicine

VEGF: Vascular endothelial growth factor

WMDs: Weighted mean differences.

YQP: Yuquan Pill.

\section{Conflicts of Interest}

The authors declare that there are no conflicts of interest.

\section{Authors' Contributions}

SP and YL conceived the study. JK, HY, and GX conducted this meta-analysis. $\mathrm{ZX}$ and $\mathrm{X}-\mathrm{YZ}$ drafted the manuscript. $\mathrm{X}-\mathrm{GZ}$ and CX revised this article. YL supervised every procedure of this study. All the authors have approved the final manuscript and decided to submit it for publication.

\section{Acknowledgments}

This study was funded by Science and Technology Key Program of Sichuan Province (2019YFS0196), Sichuan Provincial Administration of Traditional Chinese Medicine (2021MS095 and 2021MS504), and the Science and
Technology Development Fund of Hospital of Chengdu University of Traditional Chinese Medicine (21HL04).

\section{Supplementary Materials}

Supplementary Material 1: Subgroup analysis for FBG (age). Supplementary Material 2: Subgroup analysis for FBG (different control treatment). Supplementary Material 3: Subgroup analysis for $2 \mathrm{hPG}$ (age). Supplementary Material 4: Subgroup analysis for $2 \mathrm{hPG}$ (different control treatment). Supplementary Material 5: Subgroup analysis for $2 \mathrm{hPG}$ (course of treatment). Supplementary Material 6: Subgroup analysis for HbA1c (age). Supplementary Material 7: Subgroup analysis for $\mathrm{HbAlc}$ (different control treatment). Supplementary Material 8: Subgroup analysis for HbA1c (duration of disease). Supplementary Material 9: Subgroup analysis for TC (age). Supplementary Material 10: Subgroup analysis for TC (course of treatment). Supplementary Material 11: Subgroup analysis for CRP (age). Supplementary Material 12: Subgroup analysis for CRP (safety). Supplementary Material 13: Subgroup analysis for CRP (region). Supplementary Material 14: Subgroup analyses for overall effective rate (age). Supplementary Material 15: Subgroup analyses for overall effective rate (different control treatment). Supplementary Material 16: Subgroup analyses for overall effective rate (course of treatment). Supplementary Material 17: Subgroup analyses for overall effective rate (region). (Supplementary Materials)

\section{References}

[1] L. Chen, R. M. Islam, J. Wang et al., "A systematic review of trends in all-cause mortality among people with diabetes," Diabetologia, vol. 63, no. 9, pp. 1718-1735, 2020.

[2] G. Chao, Y. Zhu, and L. Chen, "Role and risk factors of glycosylated hemoglobin levels in early disease screening," Journal of diabetes research, vol. 2021, Article ID 6626587, 2021.

[3] D. J. Magliano, R. M. Islam, E. L. M. Barr et al., "Trends in incidence of total or type 2 diabetes: systematic review," BMJ, vol. 366, Article ID 15003, 2019.

[4] M. Lean, L. McCombie, and J. McSorely, "Trends in type 2 diabetes," BMJ, vol. 366, Article ID 15407, 2019.

[5] R. Williams, S. Karuranga, B. Malanda et al., "Global and regional estimates and projections of diabetes-related health expenditure: results from the International Diabetes Federation Diabetes Atlas, 9th edition," Diabetes Research and Clinical Practice, vol. 162, Article ID 108072, 2020.

[6] P. Saeedi, I. Petersohn, P. Salpea et al., "Global and regional diabetes prevalence estimates for 2019 and projections for 2030 and 2045: results from the international diabetes federation diabetes atlas, 9th edition," Diabetes Research and Clinical Practice, vol. 157, Article ID 107843, 2019.

[7] S. Chatterjee, K. Khunti, and M. J. Davies, "Type 2 diabetes," The Lancet, vol. 389, no. 10085, pp. 2239-2251, 2017.

[8] K. E. Bornfeldt and I. Tabas, "Insulin resistance, hyperglycemia, and atherosclerosis," Cell Metabolism, vol. 14, no. 5, pp. 575-585, 2011

[9] M. Laakso and J. Kuusisto, "Insulin resistance and hyperglycaemia in cardiovascular disease development," Nature Reviews Endocrinology, vol. 10, no. 5, pp. 293-302, 2014.

[10] V. Ormazabal, S. Nair, O. Elfeky, C. Aguayo, C. Salomon, and F. A. Zuñiga, "Association between insulin resistance and the 
development of cardiovascular disease," Cardiovascular Diabetology, vol. 17, no. 1, p. 122, 2018.

[11] E. G. Beale, "Insulin signaling and insulin resistance," Journal of Investigative Medicine, vol. 61, no. 1, pp. 11-14, 2013.

[12] A. Otamas, P. J. Grant, and R. A. Ajjan, "Diabetes and atherothrombosis: the circadian rhythm and role of melatonin in vascular protection," Diabetes and Vascular Disease Research, vol. 17, no. 3, Article ID 1479164120920582, 2020.

[13] J. A. Hirst, A. J. Farmer, R. Ali, N. W. Roberts, and R. J. Stevens, "Quantifying the effect of metformin treatment and dose on glycemic control," Diabetes Care, vol. 35, no. 2, pp. 446-454, 2012.

[14] Martin, Y. Zhou, T. Takagi, and Y.-S. Tian, "Efficacy and safety among second-generation and other basal insulins in adult patients with type 1 diabetes: a systematic review and network meta-analysis," Naunyn-Schmiedeberg's Archives of Pharmacology, vol. 394, no. 10, pp. 2091-2101, 2021.

[15] H. Wei, S. Liu, Y. Liao et al., "A systematic review of the medicinal potential of mulberry in treating diabetes mellitus," The American Journal of Chinese Medicine, vol. 46, no. 8, pp. 1743-1770, 2018.

[16] X. Tong, X. Liu, J. Wei, Q. Ni, and Q. Gao, “Guidelines for prevention and treatment of diabetes in traditional Chinese medicine," Chinese Medicine Modern Distance Education of China, vol. 9, no. 4, pp. 148-151, 2011.

[17] Y. Li, Y. Li, Y. Wang, L. Zheng, and L. Li, "Effect of modified yuquanwan combined with taohong siwutang on major cardiovascular risk factors of patients with type 2 diabetes," Chinese Journal of Experimental Traditional Medical Formulae, vol. 26, no. 19, pp. 177-182, 2020.

[18] D. Fu, Y. Zhang, D. Tang, H. Chen, J. Xu, and Z. Tan, "Study on the mechanism of Yuquan pill on prevention of diabetic chronic complications," Sichuan Journal of Physiological Sciences, vol. 35, no. 1, pp. 7-9, 2013.

[19] D. Wang, "The effects of yuquan pill on glucose and lipid metabolism in type 2 diabetes mellitus rats," Clinical Journal of Traditional Chinese Medicine, vol. 29, no. 1, pp. 88-90, 2017.

[20] C. Peng, C. Kong, M. Gao, W. Guo, L. Zhu, and Y. Li, "Clinical observation of protective effect of yuquanwan on endothelial cell of type 2 diabetic kidney disease," Chinese Journal of Integrated Traditional and Western Nephrology, vol. 16, no. 11, pp. 973-975, 2015.

[21] S. Luo, "Effect of yuquan pill on serum inflammatory factor, $\beta 2$-microglobulin, VEGF, IGF- 1 and serum TNF- $\alpha$ in patients with type 2 diabetic nephropathy," Guiding Journal of Traditional Chinese Medicine, vol. 23, no. 15, pp. 106-108, 2017.

[22] C. Peng, M. Gao, C. Kong, W. Guo, S. Ke, and Y. Zhou, "Clinical observation of influence of yuquanwan decoction on inflammatory cytokines in type 2 diabetic kidney disease," Journal of Nanjing University of Traditional Chinese Medicine, vol. 32, no. 2, pp. 122-124, 2016.

[23] X. Mai, X. Deng, X. Luo, and F. Chen, "Research progress on treatment of type 2 diabetes with yuquan pill," Chinese $\mathrm{Na}$ turopathy, vol. 28, no. 18, pp. 107-109, 2020.

[24] C. Li and L. Yang, "Clinical observation on 40 cases of type 2 diabetes mellitus with deficiency of qi and yin treated with yuquan pill," Yunnan Journal of Traditional Chinese Medicine and Chinese Herbal, vol. 41, no. 3, pp. 51-54, 2020.

[25] H. Lv, "Effect of yuquan pill decoction combined with candesartan cilexetil on renal function, inflammatory factors and HOMA-IR in patients with diabetic nephropathy," Journal of Guangming Traditional Chinese Medicine, vol. 34, no. 2, pp. 286-288, 2019.
[26] Y. Han, "Therapeutic effect of yuquan pill decoction combined with candesartan cilexetil on diabetic nephropathy and the influence on renal function," Journal of New Medicine, vol. 29, no. 5, pp. 545-546, 2019.

[27] L. Shamseer, D. Moher, M. Clarke et al., "Preferred reporting items for systematic review and meta-analysis protocols (PRISMA-P) 2015: elaboration and explanation," BMJ, vol. 350, Article ID g7647, 2015.

[28] American Diabetes Association, "2. Classification and diagnosis of diabetes: standards of medical care in diabetes-2021," Diabetes Care, vol. 44, no. Suppl 1, pp. S15-S33, 2021.

[29] T. J. Higgins, J. Thomas, M. Cumpston, and J. Chandler, Cochrane Handbook for Systematic Reviews of Interventions Version 6.0, https://training.cochrane.org/handbook, 2019.

[30] X. Sun, M. Briel, S. D. Walter, and G. H. Guyatt, "Is a subgroup effect believable? Updating criteria to evaluate the credibility of subgroup analyses," BMJ, vol. 340 , no. mar30 3, p. c117, 2010.

[31] Q. Zhang, K. Lin, T. Wu, R. Wang, L. Pu, and W. Li, "Effect on insulin resistence in type 2 diabetes with the treatment of yuquan pill," Practical Journal of Clinical Medicine, vol. 4, no. 5, pp. 80-81, 2007.

[32] K. Lin and Q. Zhang, "Effect of yuquan pill on blood glucose fluctuation in type 2 diabetes mellitus," Sichuan Medical Journal, vol. 35, no. 8, pp. 1032-1033, 2014.

[33] W. Chen and X. Lin, "Clinical observation of yuquan pill combined with acupoint injection in diabetic pruritus," Chinese Journal of Biochemical Pharmaceutics, vol. 36, no. 10, pp. 102-104, 2016.

[34] Z. Gao, "Clinical observation on therapeutic effect of jiangtang huayu decoction on diabetic glucose and peripheral neuropathy," Journal of Chengdu University of Traditional Chinese Medicine, vol. 25, no. 1, pp. 20-21, 2002.

[35] B. Li, H. Shen, and Y. Chen, "Clinical study on 300 case of type II diabetes treated with compound rhubarb preparation," Hebei Journal of Traditional Chinese Medicine, vol. 19, no. 2, pp. 4-5, 1997.

[36] X. Mao, "Clinical observation of erdong capsule on patients with type II diabetes mellitus," Clinical Research of Traditional Chinese Medicine, vol. 3, no. 8, pp. 51-52, 2011.

[37] L. Yang, "Analysis of clinical efficacy and blood glucose control effect of modified yuquan pill decoction on 126 cases of diabetes," Laboratory Medicine and Clinic, vol. 13, no. 13, pp. 1856-1858, 2016.

[38] S. Shi, "30 cases of diabetes treated with reinforcing the spleen and ascending the clear methods - - a comparative study of 30 cases treated with yuquan pill," Zhejiang Journal of Traditional Chinese Medicine, vol. 35, no. 2, p. 52, 2000.

[39] Z. Gao, T. Luo, and C. Ye, "Effect of Yuquan Pill on blood glucose fluctuation of diabetes mellitus patients receiving insulin therapy with deficiency type of qi and yin," Chinese Traditional and Herbal Drugs, vol. 46, no. 15, pp. 2275-2278, 2015.

[40] Y. Zheng and D. Huang, "Effects of yuquan pill on the index of kidney injury of early diabetic nephropathy," Research and Practice on Chinese Medicines, vol. 19, no. 2, pp. 42-44, 2005.

[41] H. Wang, "Effect of yuquan pills for treating T2DM patients with poor glucose control and its influence on levels of malondialdehyde and hs-CRP," China Pharmaceuticals, vol. 26, no. 24, pp. 58-60, 2017.

[42] A. Tian, "Therapeutic effect of Yuquan pill on type 2 diabetes and its influence on leptin and adiponectin," Chinese Journal of Basic Medicine in Traditional Chinese Medicine, vol. 19, no. 2, pp. 1433-1434, 2013. 
[43] Y. Deng, X. Fan, G. Wu, and F. Xiong, "Effect of yuquan pill on proinflammatory cytokines in patients with type 2 diabetes mellitus," Chinese Journal of Integrated Traditional and Western Medicine, vol. 26, no. 8, pp. 706-709, 2006.

[44] H. Wan, S. Yan, and Z. Yan, "Clinical study on Yuquan Pills combined with dapagliflozin in treatment of type 2 diabetes mellitus," Drugs and Clinic, vol. 36, no. 2, pp. 274-278, 2021.

[45] D. Xiao, X. Wang, C. Liang, Y. Wang, and T. Wang, "Clinical study on Yuquan Pills combined with saxagliptin in treatment of type 2 diabetes mellitus in elderly patients," Drugs and Clinic, vol. 36, no. 1, pp. 100-105, 2021.

[46] C. Zhao, Z. Ma, Y. Chen, and Y. Chen, "Summary of 48 cases of type 2 diabetes treated with yuquan pill combined with metformin," Hunan Journal of Traditional Chinese Medicine, vol. 24, no. 3, pp. 31-33, 2008.

[47] S. Li and N. Wu, "Clinical observation on treatment of type 2 diabetes with yuquan pill and metformin," Journal of Liaoning University of Traditional Chinese Medicine, vol. 14, no. 12, pp. 163-164, 2012.

[48] X. Jing, L. Wang, and S. Yuan, "Clinical effect and therapeutic safety analysis of yuquan pill in the treatment of type 2 diabetes," New World of Diabetes, vol. 22, no. 9, pp. 65-66, 2019.

[49] B. Zhu, "Observation on therapeutic effect of yuquan pill combined with western medicine on diabetes," Shanxi Journal of Traditional Chinese Medicine, vol. 36, no. 4, pp. 403-405, 2015.

[50] C. Colalto, "What phytotherapy needs: evidence-based guidelines for better clinical practice," Phytotherapy Research, vol. 32, no. 3, pp. 413-425, 2018.

[51] K.-W. Ng, Z.-J. Cao, H.-B. Chen, Z.-Z. Zhao, L. Zhu, and T. Yi, "Oolong tea: a critical review of processing methods, chemical composition, health effects, and risk," Critical Reviews in Food Science and Nutrition, vol. 58, no. 17, pp. 2957-2980, 2018.

[52] M. Zhang, C. Zhao, C. Zhao et al., "Determination of water content in corn stover silage using near-infrared spectroscopy," International Journal of Agricultural and Biological Engineering, vol. 12, no. 6, pp. 143-148, 2019. 